
\title{
Qualitative Modeling of Burden and Distress among Home Helpers in Japan
}

Yoshihisa Hirakawa ${ }^{{ }^{*}}$,Takaya Kimata ${ }^{2}$ and Kazumasa Uemura ${ }^{1}$

${ }^{1}$ Center for postgraduate clinical training and career development, Nagoya University Hospital, Japan

${ }^{2}$ Aoi home clinic, Japan

\begin{abstract}
Background: Although a number of studies have explored the issue of home help service for elderly care, very few studies have deeply investigated the emotional or psychological wellbeing of home helpers; in Japan specifically, the burden and distress of home helpers is still unknown. The present study aims to reveal the emotional and psychological profile of home helpers.

Methods: The authors used qualitative data based on the retrospective abduction of a one-hour focus group discussion on burden and distress among home helpers held in and around the city of Nagoya in 2012. The group discussion was entitled "Define the burden and distress of home helpers". A total of 14 participants, 12 females and 2 males, agreed to take part in the study.

Results: Nine groups were extracted: 1) Relations between home helpers and users are not always smooth; 2)There is communication gap between home helpers and their colleagues; 3)Offering customized support to users and families is difficult; 4)Home helpers have tight schedules; 5) Home helpers are treated badly; 6) Poor support from management; 7) Users and families don't understand the public long-term care insurance system and need home helpers to constantly clarify it; 8) Home helpers often fail to provide the care services requested by users for lack of time; 9) Home helpers always feel isolated and worry about providing appropriate care.

Conclusion: The results suggest that home helpers work in an environment where they have to endure hard labor, heavy pressure, and lack of sympathy.
\end{abstract}

\section{Introduction}

Although the structure and organization of home help services show large local and regional variations both within and between countries [1], Many countries are facing a growing number of elderly in need of home care assistance from others to perform day-today activities [1-3]. A home helper is a person hired to help with housework or the care of elderly people with special needs [1,2,4-6]. A home helper provides respite and support for informal caregivers, and allows home elderly patients to continue living in their community as independently as possible [2,4,7]. Some studies have explored the issue of home help service for elderly care [2,5,7-9]. For example, in Japan, Hongo et al. conducted a questionnaire survey concerning the role of home helpers in home end-of-life care; the study revealed that home helpers are expected to provide total care and assume a number of roles including that of being a good mediator able to ease end-oflife [5]. In Spain, Carretero et al. reported that home help services improve the quality of life of users and caregivers [2]. Thus, home helpers are important home care providers who are deeply involved in the lives of the elderly and their family.

Up to present, very few studies have deeply investigated the emotional or psychological wellbeing of home helpers; in Japan specifically, the burden and distress of home helpers is still unknown. By using a qualitative analysis, the present study aims to reveal the emotional and psychological profile of home helpers in Japan.

\section{Methods}

\section{Data collection}

The authors used qualitative data based on the retrospective abduction of a one-hour focus group discussion on burden and distress among home helpers held in and around the city of Nagoya in July 2012. The group discussion was entitled "Define the burden and distress of home helpers" and was held following a workshop on dementia and elderly care attended by home helpers. Workshop participants were recruited from all of the 1223 home helper stations of Aichi prefecture. A total of
14 participants, 12 females and 2 males, agreed to take part in the study.

For the discussion, participants were divided into two smaller groups of 7 people. The brainstorming method was adopted to elicit their views, as this is the most suited format for discussions among participants from various organizations. The rules of the discussion were: "express all of your thoughts," "withhold criticism," "welcome unusual views," and "combine and improve ideas." Also, to stimulate dialogue, participants were required to take turns voicing a burden or distress experienced by home helpers. Each participant was required to enumerate at least six burdens or distresses. The exchange of ideas continued until none of the participants had any more original ideas to share. Each group made a list of all the burdens or distresses outlined in each group. Each of the burdens and distresses listed were then transferred onto individual labels. In cases where the details were omitted or too difficult to understand, the authors revised the labels referencing to the discussion. In the end, there were 62 labels in total displaying the burdens and distresses experienced by home helpers.

\section{Abduction by KJ method}

The authors used the KJ method as a qualitative research tool. The concept and background of the method has been explained elsewhere [10]. In summary, the KJ method was created in the 1960 s by Japanese ethnologist Jiro Kawakita. The method is now widely employed in Japan as a tool for qualitative research and improvement of business operation. The method gathers information from the scene as it is, and is inspired from chaotic data. It is not based on fixed

"Corresponding Author: Dr. Yoshihisa Hirakawa, Center for postgraduate clinical training and career development, Nagoya University Hospital, 65 Tsuruma-cho, Showa-ku, Nagoya, Aichi, 466-8560, Japan, Tel: +81-52-744-2644; Fax: +81-52744-2997; E-mail: y.hirakawa@med.nagoya-u.ac.jp

Citation: Hirakawa Y, Kimata T, Uemura K (2015) Qualitative Modeling of Burden and Distress among Home Helpers in Japan. Int $J$ Nurs Clin Pract 2: 111. doi: http://dx.doi.org/10.15344/2394-4978/2015/111

Copyright: @ 2015 Hirakawa. This is an open-access article distributed under the terms of the Creative Commons Attribution License, which permits unrestricted use, distribution, and reproduction in any medium, provided the original author and source are credited. 
quantitative data and it does not aim to verify a hypothesis but rather to inspire one. The KJ method allows for information and ideas to be synthesized into a conceptual visual map using labels. The authors used the KJ method as an abduction tool because this method is best suited to sort through creative ideas and formulate hypotheses on complex issues from discussions with small numbers of participants.

Although this popular method is widely used, there is only a very limited amount of literature explaining the standardized method procedure in detail. Therefore, both the first author of the present study and a research assistant completed an eighteen-hour KJ method training course for researchers at the $\mathrm{KJ}$ method training center in Kyoto.

The first author and the research assistant performed the abduction. As mentioned above, the authors compiled a total of 62 labels reflecting the burdens and distresses of home helpers. The authors organized the labels into groups using the following KJ method procedure: 1) read the labels silently to understand the entire image, 2) combine labels that share a strong similarity of quality, 3) set aside any label that stands apart ('loner'), 4) make a 'first-step nameplate' for each group of labels, 5) again, read the loner labels and first-step nameplate labels silently and combine labels that share a strong similarity of quality, 6) set aside any label that stands apart, 7) after further reflection, make a 'second-step nameplate' for each group of labels. When grouping the labels, the authors endeavored not to follow standardized, stereotypical perceptions. Because the KJ method treats a loner label as a group the authors ended up with nine groups (including one loner label) following group organization. Third, the authors subjectively arranged the nine groups with nameplates onto a large sheet of paper, paying attention to the inter-relationships between each group. Subsequently, the authors explained the work result to all the study participants to confirm the objectivity of it. Finally, to confirm the clarity and cohesion of the group arrangement to study participants, the authors added a title that captured the overall message of the illustration and the relationships among the organized groups.

The present study was approved by the Institutional Review Board of Nagoya University Graduate School of Medicine.

\section{Results}

As shown in Figure 1(View supplementary file), nine groups were extracted. The results suggest that home helpers work in an environment where they have to endure hard labor, heavy pressure, and lack of sympathy.

\section{Group organization}

\section{Relations between home helpers and users are not always smooth}

The first-step nameplates "Some users hate relying on home helpers" and "Home helpers often fail to develop a good communication with users", and the label "Home helpers cannot spare the time to actively listen to users' needs" suggest that there are language and psychological communication barriers between home helpers and users.

\section{There is communication gap between home helpers and their} colleagues

This group includes the first-step nameplates: "Home helpers find it difficult to cooperate with one another, and "Home helpers find it difficult to share information with their peers".

\section{Offering customized support to users and families is difficult}

The first-step nameplate "Offering customized support for each user is difficult", "Users' families often show a non-cooperative attitude", "Home helpers do not always succeed in feeding users", and "Home helpers find it difficult to prepare meals suited to users' preferences" suggest that home helpers find it very difficult to offer customized user support.

\section{Home helpers have tight schedules}

This group includes the first-step nameplate "Home helpers do not have enough time to study about care or to receive care training", "Home helpers work on very tight schedules", "Home helpers' working hours are too long", "The shortage of home helpers is serious", and "Home helpers are unable to take any days off". These nameplates suggest that home helpers are too busy to maintain a balanced life.

\section{Home helpers are treated badly}

The first-step nameplates "A home helper is a poorly-paid lowlevel worker" included "Home helpers find their wages too low" and "Home helpers occupy the lowest rank in the system". The labels "Home helpers wish to have access to a parking spot when providing home care" and "Home helpers sometimes have insufficient work and fail to earn decent wages," as well as the first-step nameplates suggest the poor on-the-job treatment given to home helpers.

\section{Poor support from management}

The labels "Person in charge fails to respond to the authors' requests in a timely manner" and "Care provision policy for the year has not been adopted" suggest poor support on the part of management.

Users and families don't understand the public long-term care insurance system and need home helpers to constantly clarify it

This group includes "Users and families do not understand the public long-term care insurance system" and "Home helpers find it difficult to explain the public long-term care insurance system to users and families".

\section{Home helpers often fail to provide the care services requested by users for lack of time}

This group includes two first-step nameplates which highlight the fact that home helpers are often unable to perform all of the services requested by users either due to the huge volume of work and to sheer lack of time.

\section{Home helpers always feel isolated and worry about providing appropriate care}

The two first-step nameplates "Home helpers lack awareness of how their peers are doing" and "Home helpers should be encouraged to look after themselves" as well as the three labels "Home helpers sometimes face a dilemma between user and family", "Home helpers find it difficult to decide how much support users need especially during feeding service," and "Home helpers are sometimes requested to perform tasks they feel do not need to be done, like cleaning a spotless home" suggest that home helpers feel isolated and worry about providing appropriate care.

\section{Data interpretation}

The figure 2 resulting from the group organization and the title 


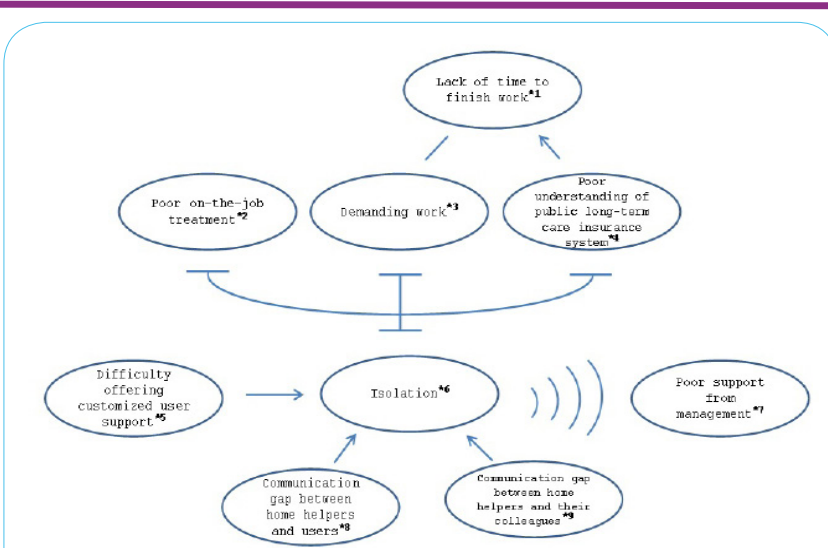

Figure 2: Illustrated figure of qualitative modeling of burden and distress among home helpers in Japan.

*1) Lack of time to finish work: The catchphrase of 2nd-step nameplate "Home helpers often fail to provide the care services requested by users on time, ${ }^{\star} 2$ ) Poor on-the-job treatment: The catchphrase of 2 nd-step nameplate "Home helpers are treated poorly", 3 ) Demanding work: The catchphrase of 2 nd-step nameplate "Home helpers have a tight schedule", ${ }^{\star} 4$ ) Poor understanding of public long-term care insurance system and need home helpers: The catchphrase of Ind-step nameplate "Users and families often do not understand the public long-term care insurance system and need home helper to clarify it",*5) Difficulty offering customized user support: "the catchphrase of 2nd-step nameplate" Home helpers cannot offer customized support to users and families", 6 ) Isolation: The catchphrase of 2nd-step nameplate "Home helpers feel isolated and worry about providing appropriate care". *7) Poor support from management: catchphrase of 1st-step nameplate "Person in charge is slow in responding to requests", 8 Communication gap between home helpers and users: The catchphrase of 2 nd-step nameplate "Relations between home helpers and users are not always smooth",*9) Communications gap between home helpers and their colleagues: The catchphrase of 2 nd-step nameplate "There is communication gap between home helpers and their peers"

"Helpless helpers". For various reasons, home helpers often fail to cultivate satisfying relations with users, even more so with users with communication difficulties. Also, home helpers often find it difficult to get along with their peers. Moreover, they are not always able to build a relationship of mutual trust with users and families. Home helpers therefore feel isolated and resentful about the lack of assistance from their superiors.

Home helpers are psychologically affected by the pressures of their work and feel that they are not receiving the support they should. They also feel that users and families have little understanding of the public long-term care insurance system, and find it difficult to have to repetitively explain the details of the programs to them. Their lack of understanding of the system also means that users and families sometimes request services that are not covered by the insurance. The illustration shows that home helpers suffer from severe distress under the current long-term care insurance system and feel completely unsupported in their work.

\section{Discussion}

Many Japanese people wish to spend the last years of their lives at home, and their ability to do so lies in great part on the services of home helpers [5]. This is why it is important to unveil the burden that home helpers experience and find ways to alleviate their distress. By doing so, the authors will ultimately be contributing to improve the quality of life of users and their families.

The results of the present study suggest that home helpers feel isolated. Unlike long-term care facility staff, home helpers usually provide care services alone at the users' homes. Home helpers therefore find it difficult to establish any form of collaborative relationship with their peers. And yet, because two or more home helpers are often in charge of a single client, home helpers need to exchange with their peers to support each other and ensure quality of service [11]. The authors should thus develop a number of tools to promote effective communication between home helpers, such as for instance a contact notebook where treatment details and other information can be shared. The authors should also allocate regular times slots for meetings between home helpers to promote greater exchange and support.

The results also indicate that users and families have little to no understanding of the nature of home help services as outlined by the public long-term care insurance system. The role of home helpers is defined as providing assistance with bathing, excretion, feeding a grievance section. The results clearly suggest that administrators management is poor both in quality and speed, and the authors therefore believe that a management education program for administrators is greatly needed.

The present study has several limitations. First, the study participants represented a limited geographic area. Because the way people think varies according to where they live, the authors believe that additional studies are needed to determine whether the results of the present study also apply to other areas. Second, the number of the participants was limited to 14 . In qualitative methods including the KJ method, study sample size is not very important. However, the authors may not have collected enough qualitative data from the 14 participants in this study. Additional qualitative studies should be conducted, and the results should be generalized with caution. Third, the KJ method is a widely used qualitative study method in Japan, and there are many studies having to do with the method [15-17]. However, there is only a very limited amount of literature in the other countries. It is still unknown where the KJ method has the reliability or the effectiveness internationally. Lastly, because this was a retrospective study of data collected during group discussion in which everyone participated freely, the participants may have had negative feelings about their jobs and the data of the present study may therefore be biased. The authors should conduct additional prospective studies targeting a wider variety of participants such as those who require mental support or whose mental condition is well controlled. There is certainly room for improvement in the study design.

\section{Competing Interests}

The authors declare that they have no competing interests.

\section{References}

1. Westerberg K, Tafvelin S (2014) The importance of leadership style and psychosocial work environment to staff-assessed quality of care: implications for home help services. Health Soc Care Community 22: 461468.

2. Carretero S, Garcés J, Ródenas F (2007) Evaluation of the home help service and its impact on the informal caregiver's burden of dependent elders. Int J Geriatr Psychiatry 22: 738-749.

3. Martin-Matthews A, Sims-Gould J (2008) Employers, home support workers and elderly clients: identifying key issues in delivery and receipt of home support. Healthc Q 11: 69-75

4. Yasura S (2000) An analysis of public home help services and the concept of care work. Okinawa kokusai daigaku shakai bunka kenkyu, 3: 1-30.

5. Hongo S, Inoue C, Sato E (1998) Research on role of home helper in terminal care. Tokai Daigaku Kenko Kagakubu Kiyo 4: 91-99.

6. Ozawa A (2000) Effectiveness of home help service for persons with mental disorders in the metropolis. Jap J Soc Ser 2: 193-200. 
Citation: Hirakawa Y, Kimata T, Uemura K (2015) Qualitative Modeling of Burden and Distress among Home Helpers in Japan. Int J Nurs Clin Pract 2: 111. doi: http://dx.doi.org/10.15344/2394-4978/2015/111

7. Hatta K (2004) Actual conditions of housework assistance and issues on supporting independent living in home-visit care: based on the research of service users and home-helpers. Annual bulletin of Osaka Junior College of Social Health and Welfare, 2: 60-69.

8. Harada $\mathrm{H}$, Konishi M (2002) Collaboration between the visiting nurse and the home helper in domiciliary care of the elderly. J Health Sci 2: 57-63.

9. Agenosono Y (1999) A Study on Home-help Service Education: Research and Analysis of Home-helper Training for Health Care Skills. The human welfare review, 2: 145-170.

10. Hirakawa $Y$, Uemura K (2013) A qualitative study of long-term care leaders experiences of end-of-life care provision at long-term care facilities in Japan. J Nurs Care S5-010.

11. Yamamura M, Lee $T$, Kase $H$ (2012) Characteristics of information gathering from clients with dementia by home helpers. Res $\mathrm{J}$ Care Welfare 19: $147-156$

12. Suga $Y(2012)$ The development of evaluation scale for helper coordination by home help service coordinators: Evaluative measurement of monitoring function and supervision function. Jap J Geront 34: 325-334.

13. Suga $Y$ (2007) Factor analysis of work stress among home help organizers. Res J Care Welfare 14: 143-150.

14. Ashitomi I (2005) [Examination of physical and psychological health conditions and the influence factors of home helpers]. J UOEH 27: 325338.

15. Hirakawa Y, Kimata T, Uemura K (2013) Current challenges in home nutrition support for frail elderly in Japan- A qualitative research from the point of view of care managers. Healthcare 1: 53-63.

16. Iki S, Horiguchi I, Shigematsu M, Sata T, Sugiyama K (2012) Qualitative analysis of the perception and acceptability of pathogen transport among housewives using focus group interviews. Jap J Infect Dis 65: 403-409.

17. Yoshida S, Shimizu K, Kobayashi M, Inoguchi H, Oshima Y, et al. (2014) Barriers of healthcare providers against end-of-life discussions with pediatric cancer patients. Jpn J Clin Oncol 44: 729-735. 